\title{
TWO RECENT STORM-SURGE EPISODES IN THE ADRIATIC
}

\author{
I. MEĐUGORAC, M. PASARIĆ, Z. PASARIĆ \& M. ORLIĆ \\ Department of Geophysics, Faculty of Science, University of Zagreb, Croatia.
}

\begin{abstract}
In the recent past, two intensive episodes of high sea level occurred in the Adriatic, which affected particularly the eastern coast of the basin. The events happened on 1 December 2008 and on 1 November 2012 when the eastern-coast station Bakar recorded the two highest water levels in its operational history. Interestingly, the episodes were of milder intensity in Venice, situated at the opposite coast. The question is: why these events were so pronounced along the eastern shore and was there specific meteorological background favouring stronger flooding of the eastern Adriatic coast? The study was carried out using hourly sea-level series along both sides of the basin and ECMWF reanalysis of air pressure and wind fields. Sea level was attributed to four processes: low-frequency variability, tide, pre-existing basin-wide seiche and storm-surge activity and respective contributions to high sea-level formations were evaluated. The effects of meteorological forcings over the basin were analysed by calculating along- and across-basin wind stress with respect to local bathymetry. The two marine storms were outcome of fine interplay between the four mentioned processes. During the 2008 flood, stormsurge activity was dominant while the other components reinforced the maximum. In the 2012 episode, storm surge was intensive at most stations, but relative timing of all the components was more complex. Results also revealed one common feature that was crucial for both floods being stronger along the eastern Adriatic coast. Specifically, presence of Sirocco-wind shear induced higher-than-usual water level rise along the eastern coast while transverse component of wind had a relatively small effect. This means that, at least in these two extreme episodes, transverse sea-level slope in the Adriatic was more sensitive to shear of longitudinal component of wind than to wind's direction.
\end{abstract}

Keywords: acqua alta, Adriatic Sea, Sirocco-wind shear, storm surge.

\section{INTRODUCTION}

High-sea-level events in the Adriatic, known as the acqua alta phenomena, occur several times a year, usually during late autumn and winter [1]. They cause flooding of the northern Adriatic cities, many of which are of historical significance. The city of Venice and its surrounding low-lying area, situated at the very north of the basin, are particularly vulnerable to these flooding episodes. Some events in the past, however, were more pronounced along the eastern Adriatic coast than in Venice, where their effect was of milder or even weak intensity. This was observed in two recent exceptional events.

In the early morning of 1 November 2012, the oldest Croatian tide-gauge station Bakar has recorded the highest water level in its operational history, when the sea level rose to 99.3 $\mathrm{cm}$ above the mean. Absolute maxima were recorded in the middle Adriatic as well, by tidegauge stations Zadar and Split. During the same event, however, Venice recorded a weaker sea-level maximum that was ranked as eleventh in recorded history [2,3]. Mediterranean cyclone active at the time brought heavy rain and strong winds over Istria in the north and Dalmatia in the middle Adriatic. Istria suffered the heaviest rainfall on the occasion. 
According to data [4], Plomin meteorological station recorded $154 \mathrm{~mm}$ of rain accumulated from midnight to the morning hours of 1 November. In the area of the Raša river, a state of emergency was declared because of an alarming increase of its upper part water levels. A tornado occurred as well, devastating villages of Šugari and Filini in eastern Istria. During the night of 1 November, the strongest wind velocities were observed in the middle Adriatic - in coastal Split and at islands of Lastovo, Palagruža, Mljet and Vis. Wind gusts in Split reached a speed of $112 \mathrm{~km} / \mathrm{h}$ while at Vis island the observed velocity was even higher - it reached $133 \mathrm{~km} / \mathrm{h}$ [4]. Normally, strong wind and low air pressure raise sea level only in the northern Adriatic, but on this occasion they also caused exceptionally high sea levels along the Dalmatian coast. The sea water was reported to enter houses, cellars, restaurants, shops and cars in several Croatian coastal cities (Rijeka, Crikvenica, Bakar, Cres, Rab, Zadar, Split...). It partially flooded the Adriatic highway in Sukošan slowing the traffic through the city [5]. Altogether, the flood of 1 November 2012 left Croatia with considerable material damage (Fig. 1, left).

Four years earlier, on 1 December 2008, another severe storm hit the Adriatic. This flood was already analysed in detail [6], and therefore only a short summary will be given in this paper. During this episode, the oldest Adriatic tide-gauge station Trieste recorded the second highest sea level in its operating history. The oldest Croatian tide-gauge station Bakar has recorded the second highest level as well. Venice experienced a less dramatic event, with sea level ranking the fourth highest in history. Similarly as in 2012, Dalmatia was flooded together with Istria and Kvarner area. Croatian contemporary newspapers reported on troubles brought by severe weather to residents of the coastal area. The old town of Trogir was flooded together with the centre of Rijeka (Fig. 1, left), as were parts of Pula, Vodice, Šibenik and Zadar. As examples of intensity of the storm, some of the ferry routes from Zadar were temporarily cancelled, and a fishing boat was thrown ashore near Kraljevica [7].
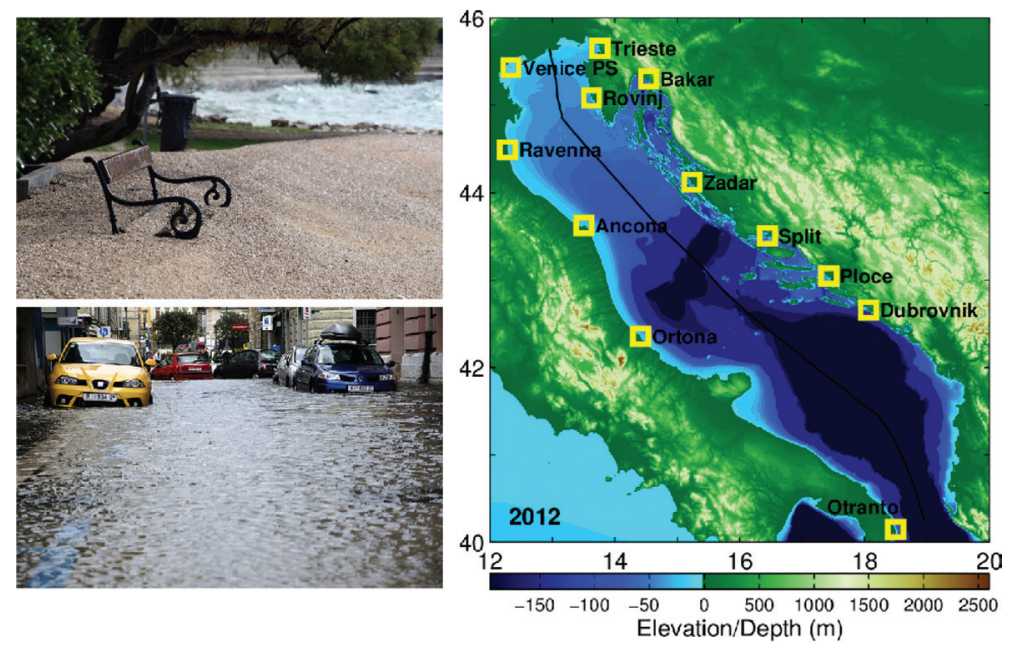

Figure 1: A scene from Zadar after the flood of 1 November 2012 (left, top). City of Rijeka during the flood of 1 December 2008 (left, bottom). Right: location of tide-gauge stations from which the sea-level data were collected for analysis of the 2012 flood. The along-basin line is needed for the purposes of Fig. 4. Same colour is used for all depths greater than $250 \mathrm{~m}$. 
In this paper, we closely analyse the flood of 1 November 2012, using hourly sea-level series, recorded at the eastern and the western coast, and complemented by ERA-Interim meteorological dataset. The results are then compared to those obtained from the study of the 1 December 2008 flood [6]. This comparison should indicate common features of the two meteorological backgrounds that led to stronger flooding of the eastern as opposed to the western Adriatic coast.

High sea levels in the northern Adriatic (acqua alta) are result of superposition of several processes: storm surge, tide, pre-existing Adriatic-wide seiche and low-frequency variability.

Storm surge has a dominant role in formation of high sea level, whereas the other processes can either amplify or mitigate the effect. The meteorological background favouring storm surges in the northern Adriatic is well established [1, 8, 9]. It develops when cyclone approaches the basin from the west, resulting in air-pressure gradient along the Adriatic which causes south-easterly wind known as Sirocco. Low air pressure in the north together with Sirocco wind accumulates water in the closed and relatively shallow north end of the basin (Fig. 1, right).

Adriatic tide reinforces flooding event if its culminating phase is superimposed on the induced storm surge [10]. The tide in the Adriatic is of mixed type and has traditionally been modelled as a superposition of seven constituents (M2, S2, N2, K2, K1, P1, O1). Its amplitude reaches the maximum at the closed north end of the basin so that tidal range in the Gulf of Trieste is larger than $1 \mathrm{~m}$.

To a much lesser degree, pre-existing Adriatic-wide seiche, which is usually triggered by a sudden weakening of Sirocco or its change to Bora wind, can take a part in an acqua alta formation as well [8]. It has period of 21-22 hours and a decay time of 3.2 days [11, 12]. Since it is a slow decaying oscillation, it could last for several days and could influence a next upcoming storm surge.

Low-frequency sea-level oscillations, which are induced by slow atmospheric planetary waves travelling to the east, are known to contribute to all coastal floods [10]. Whereas atmospheric planetary waves are prominent in the middle troposphere, they can also be observed in surface air pressure and wind velocities at temporal scales of weeks to several months.

\section{DATASET AND METHODOLOGY}

The flood of 1 November 2012 was analysed using 1-hourly sea-level series at the stations along both sides of the Adriatic (Fig. 1, right). The time interval used is four months long: from 2 September to 30 December 2012. The verification of the time series was performed with Tukey 53H filter [13] and no outliers were found. Occasional single missing values were linearly interpolated.

First, the data were reduced to anomalies by subtracting the respective four-month means. After that, the four contributing processes have been determined as previously described [6]: first the tide was synthesised using seven constituents, then the low-frequency variability was extracted by applying low-pass filter, upon which a pre-existing Adriatic seiche was estimated. Storm-surge activity was defined as the residual sea level after the three processes were removed from the series.

Meteorological dataset consists of ECMWF reanalysis [14] - the ERA-Interim surface wind and mean sea-level pressure fields given with 6 hour time step and $0.25 \times 025$ deg spatial resolution. The wind field was enhanced by a factor of 1.47 as suggested in the literature [6]. In order to examine forcing on longer spatial and temporal scales, we inspected 
geopotential hight of 500-hPa surface in addition to surface fields. All times in this paper are given in UTC.

Similar dataset and methods were used in analysis of the 1 December 2008 flood [6].

\section{RESULTS}

In the morning hours of 1 November 2012, tide-gauge stations in the whole Adriatic recorded raised sea level (Fig. 2). The maximum in Bakar was observed at 6:00 am and it was $99.3 \mathrm{~cm}$ above respective mean. At northern stations, Trieste and Rovinj, maxima were reached later, at 7:00 and 8:00 am respectively, and were lower than in Bakar - sea level was $93.6 \mathrm{~cm}$ high in Trieste and $88.6 \mathrm{~cm}$ in Rovinj. In Venice, the maximum was recorded earlier, at 1:00 am.

According to ECMWF charts, before the decisive cyclone crossed the basin, a low-pressure system born in the western Mediterranean, propagated towards the Gulf of Genoa where it remained from 27 to 29 October. It caused a rise of the water in the Adriatic and probably triggered the Adriatic seiche. The system diminished on 29 October while moving towards the south. After that, on 31 October, a cyclone developed in the western Mediterranean as a part of a larger low-pressure system centred above Scotland. From there, it moved towards the Adriatic, crossing its northern border at 6:00 am on 1 November.

The cyclone induced an air-pressure gradient over the basin, oriented in the west-to-east direction, and giving rise to Sirocco wind of non-uniform speed (Fig. 3, left). In the velocity field, south-easterly direction dominated over the larger portion of the basin, whereas north-eastern direction occurred over the northern Adriatic. The velocity field reached maximum speed, about $20 \mathrm{~m} / \mathrm{s}$, around the latitude of Zadar, with maximum slightly closer to the eastern coast. In the northernmost part, in front of Venice and in the Gulf of Trieste, the speed was relatively low, reaching $12 \mathrm{~m} / \mathrm{s}$ or less.

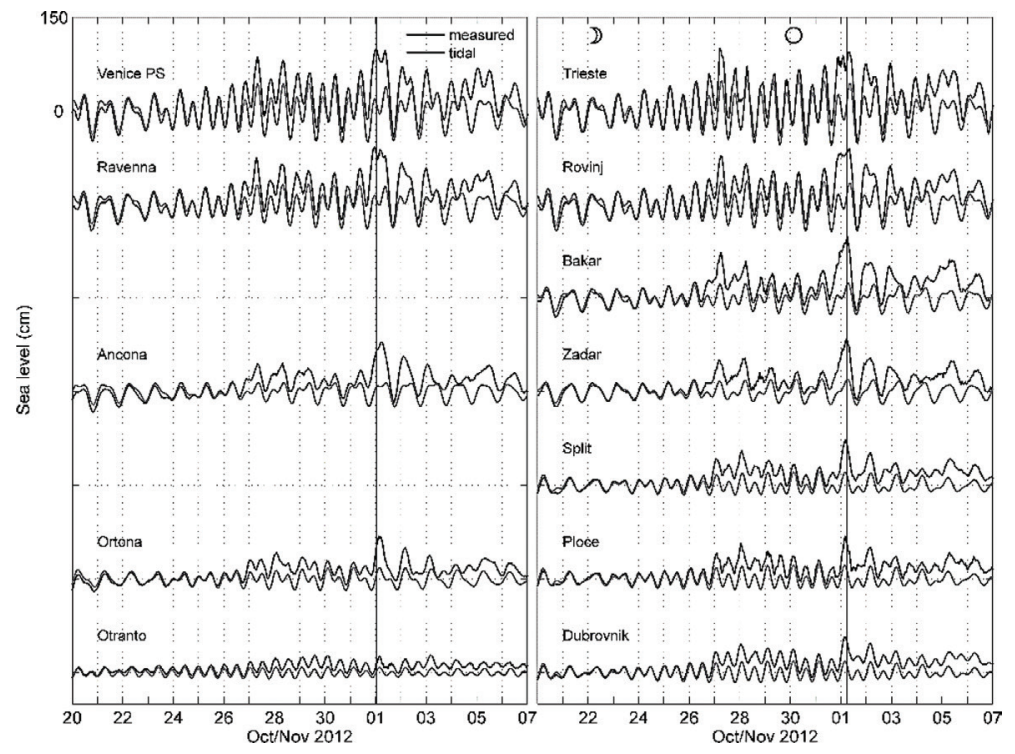

Figure 2: Measured sea-level anomalies, referred to the respective 4-month means, and tidal predictions in the Adriatic for the 2012 flood. Vertical lines indicate onset of maxima at Venice Punta Salute (left) and Bakar (right). The moon phases are also indicated in the figure. 

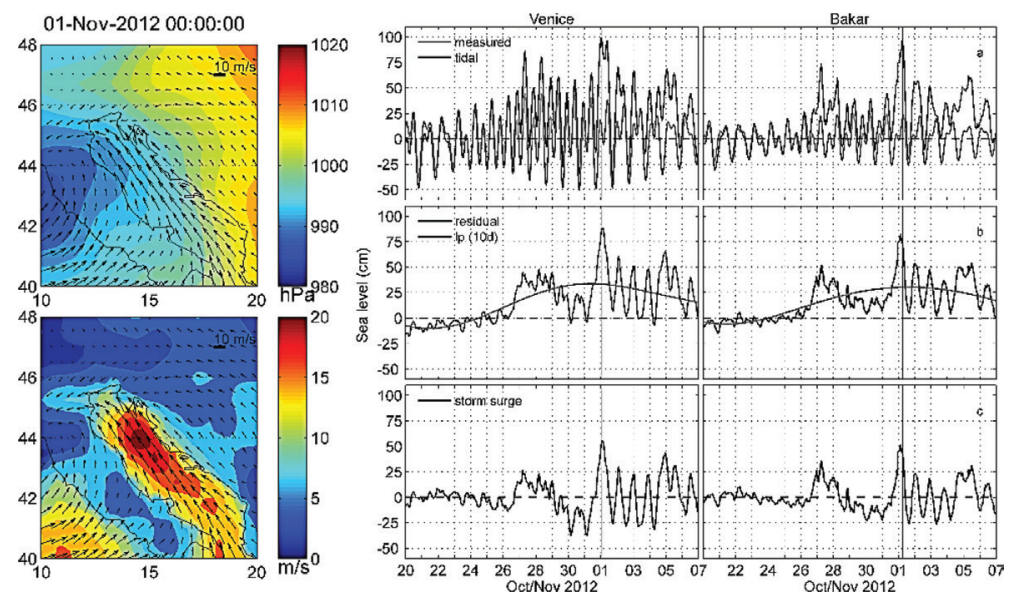

Figure 3: Left: ERA-Interim field of air pressure and enhanced wind for 1 November 2012 at 00:00 UTC. Right: sea-level evolution in Venice and Bakar - measured sea level and tidal prediction (a), sea-level residual and low-frequency sea-level change (b), storm-surge activity (c).

Preconditioning of the flooding event started a week before when the sea level began to slowly rise (Fig. 3, right) as a result of atmospheric large-scale activity. In fact, this disturbance was related to the passage of atmospheric planetary waves which can clearly be seen from the geopotential height of 500-hPa surface. Its contribution to high sea level was almost uniform along the two Adriatic coasts (Fig. 4), as expected considering that this is a largescale process. At the northern stations it contributed about $30 \mathrm{~cm}$ to the local maxima.

Residual sea-level series (Fig. 3, right) indicate a large energy input on 26 and 27 October, which coincided with the Genoa cyclone. This abrupt sea-level change generated the Adriatic-wide seiche of significant amplitude. However, this seiche was generated five days before the main event and therefore was mostly damped at the time of flooding and had almost no effect on the event.

The Moon phase was between full moon and the last quarter (Fig. 2), therefore the semidiurnal tide prevailed. Onset of maxima at all stations coincided with the positive tidal contribution, but the eastern stations were more affected by it (Fig. 4). Sea-level maxima at Trieste and Rovinj have coincided with the tidal maxima that were reached when storm surge was subsiding. On the other hand, the maximum at Venice was formed earlier in the night of 1 November, during the storm-surge peak and small tide (Figs 3 and 4). The situation in Bakar was something in between - the maximum emerged while the storm surge was subsiding and the tide was heading towards its maximum.

It is interesting to note (Fig. 3, right) that the storm surge was of similar intensity in Bakar and in Venice. One would expect a much higher storm surge in Venice because the Siroccorelated fetch is longer and the depths are smaller off it. Comparison of the storm-surge series at the eastern stations with corresponding series at the western stations indicates that the along-basin water-surface slope was not very steep while in an across-basin direction water surface was horizontal. Obviously, the wind forcing (Fig. 3, left), characterised by low speeds over the northernmost part of the Adriatic and by a maximum in the vicinity of Zadar, considerably raised water in the middle Adriatic producing the storm surge of a moderate along-basin 
140 Flood Risk Management and Response

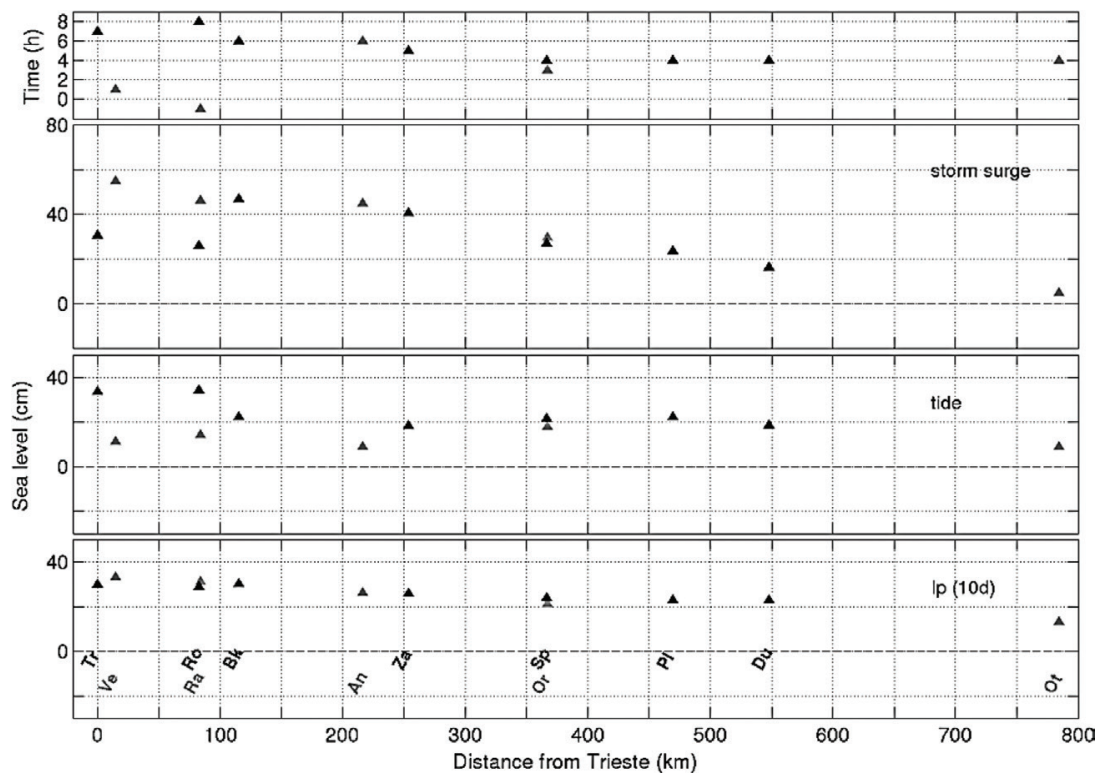

Figure 4: Contribution of each component at the onset of local sea-level maxima to the 2012 flood. Eastern Adriatic stations are denoted by black and western by grey triangles: Trieste (Tr), Venice (Ve), Rovinj (Ro), Ravenna (Ra), Bakar (Bk), Ancona (An), Zadar (Zd), Split (Sp), Ortona (Or), Ploče (Pl), Dubrovnik (Du), Otranto (Ot). Abscissa denotes a distance of a station from Trieste when a station is projected onto the along-basin line indicated in Fig. 1. Time of the occurrence of sea-level maxima is indicated at the top of the figure.

slope. Interestingly, the wind managed to accumulate water equally along the two coasts even though the eastern Adriatic is much deeper. Hence, although the eastern Adriatic maxima were influenced by the tide, they would not have been so pronounced if the storm-surge level had not been higher along the eastern coast than it usually is during Sirocco-wind episodes.

To summarise, the flooding of the north-western coast during the Adriatic marine storm of 1 November 2012 was a result of high storm surge and moderate tide, all superimposed on raised sea level due to low-frequency variability. Flooding of the eastern Adriatic coast was a result of an interplay between storm surge and tide, superimposed on prolonged interval of raised water level.

The flooding episode of 1 December 2008 was induced by Genoa cyclone that was not particularly pronounced [6]. The cyclone supported air-pressure gradient along the basin and south-easterly wind of non-uniform speed. Intensity of the wind field was generally higher along the eastern side and in the south where southerly direction was prevailing. Sea-level maxima emerged as a result of a high storm surge accompanied by a large along-basin slope, as well as of a high tide and a low-frequency sea-level rise. Pre-existing seiche was not especially strong and its contribution was rather small. An interesting fact about this event is that all components, except the storm surge, had a similar effect at both sides of the basin. This means that severe flooding of the eastern shore in 2008 resulted from rarely experienced eastward storm-surge surface slope. 


\section{DISCUSSION AND CONCLUSION}

In recent years, on two occasions (1 December 2008 and 1 November 2012) the eastern coast of northern Adriatic experienced extremely high sea level - in Bakar on both occasions it surpassed its ever recorded value - while the events were of a lower intensity at the opposite coast. The aim of our analysis was to determine specific conditions under which the floods were more pronounced along the eastern coast than at the western coast. The results showed that in both episodes the across-basin storm-surge slope was decisive for flooding of the eastern coast. The two episodes were governed by similar meteorological backgrounds. Air-pressure gradient was of along-basin (2008) or west-to-east (2012) direction, while consequent Sirocco-wind speed was spatially non-uniform with higher values near the east coast. Air-pressure forcing was in favour of higher sea level at the western coast and in both cases its contribution was estimated to be less than $10 \mathrm{~cm}$. In order to evaluate the wind-stress effect on sea level over the variable bathymetry, we mapped wind-stress-to-depth ratio shown in Fig. 5. The wind stress, calculated as described before [6], was decomposed into along- and across-basin component. Evidently, the transverse water-level slope emerged as a result of dynamics related to longitudinal wind. The Sirocco-wind shear related to stronger winds along the eastern coast surpassed the bottom-slope effect and accumulated water along the deeper eastern coast. On the other hand, the impact of transverse wind on across-basin water slope was of secondary importance since its contribution was rather small, probably due to the wind component being small and the related fetch being short.

Therefore, we can conclude that two recent episodes of severe flooding along the eastern Adriatic coast, the events of 2008 and 2012, were the result of storm surge controlled by Sirocco-wind shear superimposed on the tide and the low-frequency sea-level rise.

2012
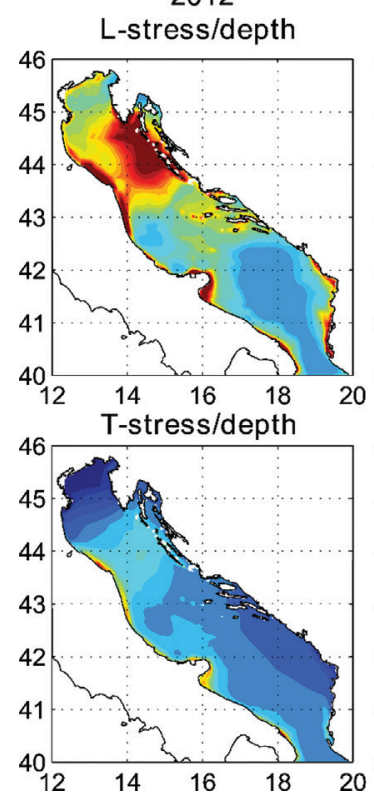

2008
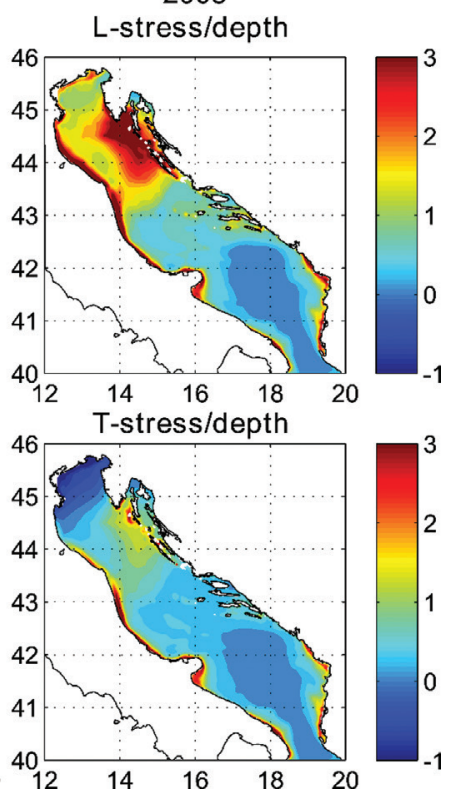

Figure 5: Along-basin (top) and across-basin (bottom) wind stress with respect to local bathymetry and normalized by average wind stress over the basin (in units $10^{-2} \mathrm{~m}^{-1}$ ) for the 2012 (left) and 2008 (right) floods. Wind stresses are related to the calibrated ERA-Interim wind fields of 1 November 2012 at 00:00 h and 1 December 2008 at 00:00 h. 


\section{ACKNOWLEDGMENTS}

The authors are thankful to the following institutions for providing the data: Consiglio Nazionale Delle Ricerche, Hydrographic Institute of the Republic of Croatia, Istituto Superiore per la Protezione e la Ricerca Ambientale and Istituzione Centro Previsioni e Segnalazioni Maree. This work has been fully supported by Croatian Science Foundation under the project 2831 (CARE).

\section{REFERENCES}

[1] Lionello, P., Cavaleri, L., Nissen, K.M., Pino, C., Raicich, F. \& Ulbrich, U., Severe marine storms in the Northern Adriatic: characteristics and trends. Physics and Chemistry of the Earth, 40-41, pp. 93-105, 2012.

http://dx.doi.org/10.1016/j.pce.2010.10.002

[2] Bonato, N., Egiatti, G., Ferla, M. \& Filippi, M., Tidal observations in the Venetian Lagoon. Update on sea level change from 1872 to 2000. Proc. of the Final Workshop of COST Action 40, eds. I. Vilibić, H.P. Plag \& M. Orlić, Hydrographic Institute of the Republic of Croatia, Split, pp. 97-105, 2001.

[3] Venice Municipality - Tide Monitoring and Forecast Center, available at http://www. comune.venezia.it/flex/cm/pages/ServeBLOB.php/L/IT/IDPagina/25419

[4] Crometeo - monitoring and forecasting the weather, available at www.crometeo.hr

[5] www.dnevnik.hr

[6] Međugorac, I., Pasarić, M. \& Orlić, M., Severe flooding along the eastern Adriatic coast: the case of 1 December 2008. Ocean Dynamics, 65, pp. 817-830, 2015. http://dx.doi.org/10.1007/s10236-015-0835-9

[7] www.jutarnji.hr

[8] Robinson, A.R., Tomasin, A. \& Artegiani, A., Flooding of Venice, phenomenology and prediction of the Adriatic storm surge. Quarterly Journal of the Royal Meteorological Society, 99(422), pp. 688-692, 1973. http://dx.doi.org/10.1002/qj.49709942210

[9] Trigo, I.F. \& Davies, T.D., Meteorological conditions associated with sea surges in Venice: a 40 year climatology. International Journal of Climatology, 22, pp. 787-803, 2002. http://dx.doi.org/10.1002/joc.719

[10] Pasarić, M. \& Orlić, M., Long-term meteorological preconditioning of the North Adriatic coastal floods. Continental Shelf Research, 21, pp. 263-278, 2001. http://dx.doi.org/10.1016/S0278-4343(00)00078-9

[11] Raicich, F., Orlić, M., Vilibić, I. \& Malačič, V., A case study of the Adriatic seiches (December 1997). Il Nuovo Cimento C, 22, pp. 715-726, 1999.

[12] Cerovečki, I., Orlić, M. \& Hendershott, M.C., Adriatic seiche decay and energy loss to the Mediterranean. Deep-Sea Research, 44(12), pp. 2007-2029, 1997. http://dx.doi.org/10.1016/S0967-0637(97)00056-3

[13] Otnes, R.K. \& Enochson, L., Applied Time Series Analysis, Wiley: New York, 1978.

[14] Dee, D.P., Uppala, S.M., Simmons, A.J., Berrisford, P., Poli, P., Kobayashi, S., Andrae, U., Balmaseda, M.A., Balsamo, G., Bauer, P., Bechtold, P., Beljaars, A.C.M., Van de berg, L., Bidlot, J., Bormann, N., Delsol, C., Dragani, R., Fuentes, M., Geer, A.J., Haimberger, L., Healy, S.B., Hersbach, H., Holm, E.V., Isaken, L., Kallberg, P., Kohler, M., Matricardi, M., Mcnally, A.P., Monge-Sanz, B.M., Morcrette, J.J., Park, B.K., Peubey, C., De Rosnay, P., Tavolato, C., Thepaut, J.N. \& Vitart, F., The ERA-Interim reanalysis: configuration and performance of the data assimilation system. Quarterly Journal of the Royal Meteorological Society, 137, pp. 553-597, 2011.

http://dx.doi.org/10.1002/qj.828 